\title{
Pregnancy related biometric changes in the ovaries and uterus of the sahelian goat
}

\author{
AZ Jaji ${ }^{1}$, RA Buduwara ${ }^{2}$, Al Akanmu², M Zachariah ${ }^{2}, \mathrm{~J} \mathrm{Luka}^{2}$ \& B Gambo ${ }^{2}$ \\ ${ }^{1}$ Department of Veterinary Anatomy, University of Ilorin, Nigeria \\ ${ }^{2}$ Department of Veterinary Anatomy, University of Maiduguri, Nigeria.
}

*Correspondence: Tel.: +2347038243997, E-mail: jajidvm@yahoo.com

\begin{abstract}
Ovaries and uteri of 40 apparently normal, sexually mature female Sahelian goats (30 pregnant and10 non pregnant) were obtained and measured, immediately after slaughter, at the Metropolitan abattoir, Maiduguri, Nigeria, over a period of one year. This was with the aim of documenting pregnancy related biometrical changes in them. The diameter and thickness of the right ovary showed extremely significant increase $(p<0.001)$ during the 14-20 weeks of gestation. The dimensions of the uterine horns showed levels of significant increases ( $p<0.05$ to $0.001)$ along the stages of gestation, those of the uterine body showed extremely significant increase $(p<0.001)$ throughout gestation, while the cervical diameter and length respectively only showed significant and very significant increases during the 14-20 weeks of gestation. Conclusively, in the Sahelian goat, pregnancy does not seem have significant effect on the dimensions and weight of the left ovary to full term but causes extremely significant increases in the diameter and thickness of the right ovary during the 14-20 weeks of gestation. The diameter and thickness of the right ovary is extremely significantly more than those of the left at the 14-20 weeks of gestation. The gravid and non-gravid right ovaries are larger in dimensions and heavier in weight as compared to left ones, which confirming the fact of right ovary being more active than the left one. Pregnancy causes levels of significant increase in the dimensions of the uterine horns, consistent extremely significant increase in the dimensions of the uterine body, along the stages of gestations. It also causes levels of significant increase in the dimensions of the cervix during the 14-20 weeks s of gestation. The right and left uterine horns of the Sahelian goat show no significant difference in dimensions both in pregnant and non - pregnant states.
\end{abstract}

Keywords: biometry, ovary, pregnancy, Sahelian goats, uterus.

\section{Introduction}

The domestic goat (Capra aegagrus hircus), a subspecies of goat domesticated from the wild goat, is a member of the Bovidae family and is closely related to the sheep as both are in the goatantelope subfamily caprinae. (Hirst, 2008). The Sahelian goat also known as Sahélienne, Cheèvre bariolée, Fulani, West African Long legged, Gorane, Niafounké and Nioro, belongs to the Savanna group of goats with many types and subtypes raised in the Saharan and sub-Saharan region (Mason, 1996).

The FAO (1991) estimated the goat populations of Africa to be 171 million, out of which 22 million were found in Nigeria. Close to 693 million goats, were kept worldwide (FAO, 2001).

Reproductive performance is economically important in small ruminant because of its effect on the number of offspring produced per year (Greyling, 2000). To maintain a good reproductive performance a clear idea about the reproductive organs of small ruminant is necessary. The biometry of genital tracts of the female reveals the overall well being of the animals. The knowledge of biometrical status of female genital tract is essential to perform artificial insemination, pregnancy diagnosis and dealing with infertility problems (Kunbhar et al., 2003) and its treatment (Kumar et al., 2004). The information on biometry of the reproductive tract of the pregnant Sahelian goat is rare in literatures. This present study aims at documenting information on the progressive biometrical changes in the ovaries and uterus during pregnancy in this breed of goat.

\section{Materials and methods}

These studies were carried out on uteri and ovaries of thirty pregnant and ten non-pregnant adult Sahelian goats at the Maiduguri Metropolitan abattoir. The animals were apparently healthy, sexually matured and of varying ages $\left(2-3 \frac{1}{2}\right.$ years and above) and weights. The organs were collected 
immediately after slaughter, scalpels and blades were used to incise, excise, separate and dissect the organs. Tanning coat and a superior tailoring rule (Butterfly Brand) were used to measure length and widths of uteri and ovaries. The ovarian thickness was measured using micrometer screw gauge (Mitutoyo Brand). Lengths of uteri and ovaries were measured in centimeters. Ovarian weights were measured in grams using electronic precision balance (Metra brand).

The 20 weeks gestation period of the Sahelian goat was divides into three stages (6-8 weeks, 8-14 weeks and 14-20 weeks). The stages of gestation were established, after biometrical measurements of the dimensions of the ovaries and uteri, by determining the age of fetuses associated with each pregnancy. This was done through comparing their crown-rump length and body weight measurements with those of the tropical caprine fetuses from the Maiduguri abattoir, as reported by Sivachelvan et al. (1996).

The length of either ovary was the distance between its anterior and posterior ends. The breath was the distance between its attached and free borders and the thickness, the distance between its medial and lateral surfaces. The length of the uterine body was the distance from the point of bifurcation of the uterine horns to the tip of internal os of the cervix and the breath was the greatest distance of its right and left walls. The length of the uterine horn was the distance from the middle of the point of bifurcation of the uterus utero-oviducal junction and the breath the distance between its right and left walls. The length of the cervix was the distance from the tip of internal os to the tip of external os of the cervix, and the breath the greatest distance of its right and left walls.

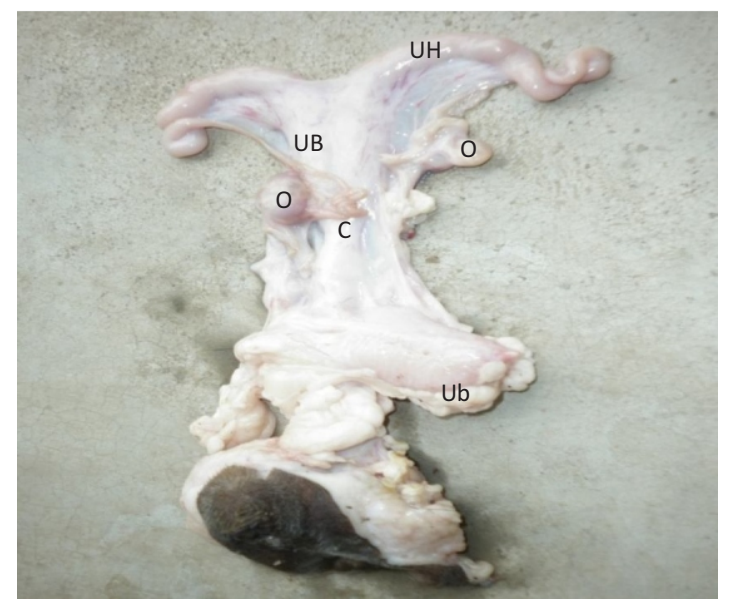

Plate 1: The reproductive system of a of a non-pregnant Sahelian doe depicting the locations of the ovary (O), uterine horn (UH), uterine body (UB), Cervix (C), Vulva $(\mathrm{Vu})$ and the urinary bladder (Ub).
The differences between the above dimensions along the three periods of gestation were tested using the ANOVA from the computer statistical software, Graph pad Instat, version 3.06, 32 bit for Windows.

\section{Results}

The left ovary (Plate 1 ) in the adult non- pregnant Sahelian goat was $1.90 \pm 0.23 \mathrm{~cm}$ in length, $1.52 \pm$ $0.28 \mathrm{~cm}$ in diameter, $0.29 \pm 0.14 \mathrm{~cm}$ in thickness and $0.71 \pm 0.22 \mathrm{~g}$ in weight. While the right ovary was found to be $2.09 \pm 0.026 \mathrm{~cm}$ in length, $1.30 \pm 0.29 \mathrm{~cm}$ in diameter, $0.19 \pm 0.16 \mathrm{~cm}$ in thickness and $0.71 \pm$ $0.18 \mathrm{~g}$ in weight. (Table 1). The diameter and thickness of the right ovary showed extremely significant increase $(p<0.001)$ at the $14-20$ weeks of gestation (Table 1).

In the non-pregnant Sahelian goat, the left uterine horn was $10.86 \pm 2.28 \mathrm{~cm}$ in length and $2.23 \pm 0.47 \mathrm{~cm}$ in diameter while the right was $11.92 \pm 2.19 \mathrm{~cm}$ in length and $2.22 \pm 0.47 \mathrm{~cm}$ in diameter. These dimensions showed levels of significant increases $(p<0.05$ to 0.001$)$ along the periods of gestation (Table 1).

The uterine body in the non-pregnant Sahelian goat was $4.19 \pm 0.82 \mathrm{~cm}$ in length and $2.92 \pm 041 \mathrm{~cm}$ in diameter These dimensions showed extremely significant increase $(p<0.001)$ along the stages of gestation (Table 1).

The cervix in the non-pregnant Sahelian goat was $5.05 \pm 1.09 \mathrm{~cm}$ in length and $2.36 \pm 0.30 \mathrm{~cm}$ in diameters. The cervical diameter and length respectively showed significant and very significant increases at the 14-20 weeks of gestation (Table 1). 
Table 1: Pregnancy related biometrical changes in the ovaries and uterus of the Sahelian goat with good body condition score in Maiduguri, Nigeria

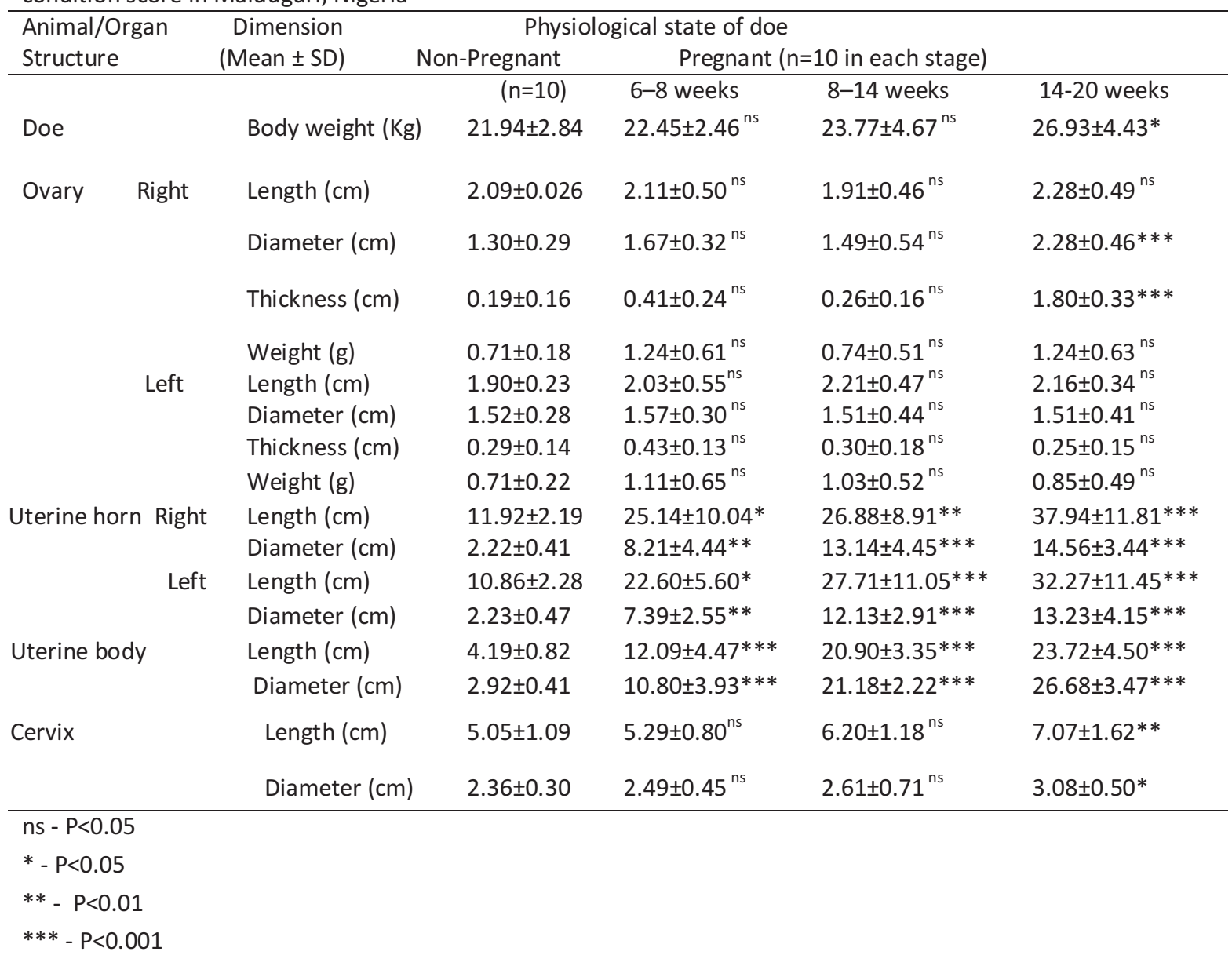

\section{Discussion}

The gravid and non-gravid right ovaries were larger in dimensions and heavier in weight as compared to left ones which confirms the fact that right ovaries are more active than the left one, in agreement with Gupta (2011), as in cow, and ewe (Pineda, 2003). The left ovary is the most active in the camel (Jaji et al., 2010) and mare and sow (Pineda, 2003).

The uterine horn of the non-pregnant Sahelian goat of the present study was observed to be of the bicornuate type, in agreement with those reported by Konig and Liebich (2004) and Leite-Browning (2009). The dimensions of the uterine horns fell within the range reported by Pineda (2003) but were however; lower to those of Adigwe and Fayemi, (2005). Feeding of goats on bush leaves, dry fodder or grasses with less supplement feeds from 2 to 3 weeks of age have been shown to cause retarded growth and development of the reproductive tract (Obwolo, 1992). This may be very applicable to the Sahelian goat, being grazed in harsh climate. The uterine horn of pregnant Sahelian goat show levels of progressive significant increases in biometric value during the stages of gestation when compared with the non-pregnant uterine horn. The uterus is a smooth, muscular organ that stretches during the pregnancy along with the growth/increase of a fetus or fetuses and associated membranes and fluids (Leite-Browning, 2009; Jaji et al., 2010).

The mean length of the uterine body of the nonpregnant Sahelian goat was lower when compared to those of Adigwe and Fayemi, (2005) but the diameter fell within their range of values and slightly lower than those values reported by Hafez, (1980). The length and diameter were however higher than those of the Black Bengali goat (Gupta, 2011). The discrepancy could be due to breed variation (Obwolo, 1992). Differences in size of reproductive tract may also be due to climatic effects as young goats in the tropics have to contend with the effects 
of the first dry season when growth may be seriously retarded. Pregnant does with higher nutritional status produce heavier kids than those with poorer nutrition (Singh et al., 1992; Oyeyemi et al.; 2001) and this may affect the size of the reproductive tract of kids that later grow to adult. The present study recorded consistent extremely significant increases in the length and diameter of the uterine body during the stages of gestation. These were also attributed to pregnancy related increase in fetal size and associated fetal membranes and fluids (Jaji et al., 2010). According to McDonald (1980), the uterus is supported by the broad ligament of the uterus which is subject to considerable stretching especially during pregnancy. In the non-pregnant states the uterus is held in the dorsal pelvic area. The uterus is a remarkable organ in that it can enlarge and extend itself to accommodate the conceptus yet retain the capacity to involute following parturition even approaching the original size and form.

The cervix of goats has an anterior and a posterior opening or os. The cervix remains closed; however, it opens during heat under the influence of the hormone estrogen to facilitate the penetration of the sperm cells. The cervix is also opened during parturition for the passage of the fetus. During pregnancy, the cervix enlarges like the uterus. The inner layer of the cervix has secretory cells that produce a thick mucus, or "plug," that accumulates during pregnancy to protect the uterine environment against pathogens or infectious agents and foreign bodies. It therefore acts as the doorway to the uterus, a physiological barrier separating the external environment from the internal environment of the animal (McDonald, 1980 and Leite-Browning, 2009). The diameter of the cervix of the nonpregnant Sahelian goat studied fell within the range reported by (Pineda, 2003). However, the length and diameters was higher than those of the Red Maradi (Adigwe and Fayemi, 2005) and the Black Bengali (Gupta, 2011) breeds of goat. The discrepancy could

\section{References}

Adigwe PI \& Fayemi O (2005). A biometric study of the reproductive tract of the red sokoto (Maradi) goats of Nigeria. Pakistan Veterinary Journal, 25(3):149-150.

Food and Agriculture Organization of the United Nations (FAO) (1990). Production Yearbook. FAO-UN Rome, Italy. Vol. 43:309.

Food and Agriculture Organization of the United Nations (FAO) (2001). Livestock and Livestock Products. Quarterly Bulletin of Statistics, 55:336 also be due to breed variation. (Obwolo, 1992; Gupta, 2011).

In the Sahelian goats, pregnancy does not seem to have significant effect on the dimensions and weights of the left ovary to full term and only causes extremely significant increases in the diameter and thickness of the right ovary at the 14-20 weeks of gestation. The gravid and non-gravid right ovaries were larger in dimensions and heavier in weight as compared to left ones, which confirms the fact that right ovaries are more active than the left one. The dimensions and weights of the right and left ovaries of the pregnant Sahelian goat show no significantly difference from the non-pregnant ones until at the 14-20 weeks of gestation when the diameter and thickness of the right ovary shows extremely significant increase over those of the left. Pregnancy causes levels of significant increase in the dimensions of the uterine horns, consistent extremely significant increase in the dimensions of the uterine body, along the periods of gestations. It also causes levels of significant increase in the dimensions of the cervix during the 14-20 week of gestation. The right and left uterine horns of the Sahelian goat show no significant difference in dimensions both in pregnant and non - pregnant states. The differences between the results in this study and published results in goats might be due to breed differences. Differences in size of reproductive tract may also be due to climatic effects as young goats in the tropics have to contend with the effects of the first dry season when growth may be seriously retarded. More work on other breeds and cross breeds and causes of differences between breeds and species seems important for better understanding of the reproduction in these animals.

\section{Acknowledgement}

The authors are grateful to the technical staff of the Department of Veterinary Anatomy, University of Maiduguri, for the assistance rendered.

Greyling, JPC (2000). Reproduction traits in the Boer goat doe. Small Ruminant Research, 36 (2).171-177.

Gupta MD, Akter MM, Gupta AD \& Das A (2011). Biometry of female genital organs of black bengal goat. International Journal of Natural Sciences, 1(1):12-16.

Hafez ESE (1980). Reproduction in Farm Animals (4 ${ }^{\text {th }}$ edition). School of Medicine Wayne State University Detroit, Michigan. Pp 627

Hirst KK (2008). The History of the domestication of goats".http://archaeology.about.com/od/do 
mestications/qt/goats.htm, retrieved 201106-15.

Jaji AZ, Kwari HD, Ribadu AY, Sivachelvan MN \& Salisu T (2010). Pregnancy Related Biometrical and Histological Changes in the Dromedary Ovaries and Uterus. Nigerian Journal of Experimental and Applied Biology, 11(2):237-245.

Konig HE \& Liebich HG (2004). Veterinary Anatomy of Domestic mammals. Schatter, New York. Pp 585-635.

Kumar S, Ahmed FA \& Bhadwal, MS (2004). Biometry of female genitalia of Murrah buffalo (Bubalus bubalis). Indian Journal of Animal Reproduction, 25(2):143-145.

Kunbhar HK, Samo MU, Memon A \& Solangi, AA (2003). Biometrical studies of Reproductive organs of Thari cow. Pakistan Journal of Biological Sciences, 6(4):322-324.

Leite-Browning ML (2009). Biology of Reproduction of Goats. Alabama Cooperative Extension System. www.aces.edu/urban, retrieved, 2011-06-15.

Mason IL (1996). A World Dictionary of Livestock Breeds, Types and Varieties. 4th edition CAB International, Pp 273.
McDonald LE (1980). Veterinary endocrinology and reproduction. Lea and Febiger, Philadelphia, USA, Pp 560.

Obwolo MJ (1992). Survey of the reproduction organ abnormalities of ewes in Zimbabwe. Bulletin of Animal Health and Production in Africa, 40:85-86.

Oyeyemi MO, Akusu MO \& Ogundipe GAT (2001). Effects and economic implications of different planes of nutrition on gestation periods and birth weights of West African Dwarf goats. Tropical Veterinarian, 19:210215.

Pineda MH (2003). Female Reproductive System. In: McDonald's Veterinary Endocrinology and Reproduction (MH Pineda \& MP Dooley, editors). lowa State University Press, lowa USA, Pp 283-321.

Singh D, Kumar P \& Singh K (1992). Kid Rearing in hot Humid and cold environments of India. In: Research in Goats: Indian Experience. Central Institute of Research on Goats, Makhdoom, Mathura, India, Pp 255

Sivachelvan MN, Ghali M \& Chibuzo GA (1996). Foetal age estimation in sheep and goats. Small Ruminant Research, 19(1):69-76. 